\title{
A utilização do pronome me na fronteira sul do brasil: estudo de caso da cidade de Jaguarão $R S$
}

\author{
La utilización del pronombre me en la frontera sur del Brasil: estudio de \\ caso de la ciudad de Jaguarão RS \\ The use of me on the southern border of Brazil: a case study in Jaguarão \\ $R S$
}

\author{
Jairo de Almeida Santana ${ }^{1}$ \\ Dra. Leonor Simioni ${ }^{2}$
}

\begin{abstract}
Resumo
Nesta pesquisa, é analisado o uso do clítico de primeira pessoa do singular me no contexto da cidade de Jaguarão, RS, fazendo um contraponto com outras regiões brasileiras, em que se percebe um uso distinto, tanto na estrutura frasal quanto no apagamento deste pronome. Justifica-se a pesquisa pelo fato de os forasteiros, ao entrarem em contato com o contexto linguístico de Jaguarão, estranharem alguns usos deste pronome. Para tanto, utiliza-se de preceitos dos estudos sociolinguísticos, que identificam esta ocorrência como variação diatópica. Em sua análise, não se consideraram variáveis extralinguísticas, como, por exemplo: gênero, idade, ou grau de escolaridade, por se perceber que elas não influenciam no uso do pronome. Por meio dos dados coletados, podese perceber que o pronome átono me é constantemente utilizado no espaço fronteiriço jaguarense, com diferentes funções sintáticas (complemento verbal, dativo ético, entre outras); o estranhamento de quem chega a esta região está relacionado à diminuição do uso dos pronomes oblíquos em outras regiões, caracterizando, assim, uma variável linguística particular dessa região. Nota-se ainda que, atualmente, o uso do pronome me é característico da região sul do Brasil, com grande ocorrência em Jaguarão.
\end{abstract}

Palavras-Chave: Sociolinguística; variedade linguística; pronome me.

\section{Resumen}

En esta pesquisa, se analiza el uso del clítico de primera persona del singular me en el contexto de la ciudad de Jaguarão, RS, haciendo un contrapunto con otras regiones brasileñas, en que se percibe un fenómeno distinto, tanto en la estructura de la frase como de su apagamiento. La pesquisa se justifica por los forasteros, al entraren en contacto con el contexto lingüístico de Jaguarão, extrañaren algunos usos de este pronombre. Para tanto, se utiliza de preceptos de los estudios sociolingüísticos, que identifican esta ocurrencia como variación "diatópica". En su análisis, no se consideraron variables extralingüísticas, como, por ejemplo: género, edad o grado de escolaridad, por percibir que ellas no influencian en el uso del pronombre. Por medio de los datos colectados, se pode percibir que el pronombre me es contantemente utilizado en el espacio fronterizo "jaguarense" con diferentes funciones (complemento verbal, dativo ético, entre otros); el extrañamiento de quien llega a esta región está relacionado a la diminución del uso del pronombre oblicuo en otras regiones, caracterizado, así, una variedad lingüística característica de esta región; y que, actualmente, el uso del pronombre me es característico de la región sur del Brasil, con gran ocurrencia en Jaguarão.

Palabras claves: Sociolingüística; variedad lingüística; pronombre me.

\footnotetext{
${ }^{1}$ Graduando em Letras Português e Espanhol; Universidade Federal do Pampa - Unipampa; Jaguarão, Rio Grande do Sul, Brasil; jairo.jime@yahoo.com.br.

${ }^{2}$ Doutora em Linguística; Universidade Federal do Pampa - Unipampa; Jaguarão, Rio Grande do Sul, Brasil; leonorsimioni@unipampa.edu.br.
} 


\begin{abstract}
The goal of this research is to analyze the use of first person singular pronoun me in the city of Jaguarão, RS in comparison with other brazilian regions, since they are different both in frequency of pronoun usage and in the possibility of pronoun deletion. Outsiders who come in contact with the speech of Jaguarão immediately note such differences. Since the phenomenon under analysis is a case of diatopical variation, the framework of Sociolinguistics is herein adopted, even though extralinguistic variables such as gender, age or schooling are not considered due to the fact that they do not seem to have any influence on pronoun usage. Data shows that the pronoun me is constantly used in Jaguarão, with different syntactic roles. The pronoun use is noted by outsiders because such pronouns are less frequently used in other areas of the country, leading to the conclusion that high frequency of usage of pronoun me is a linguistic trait not only of the Jaguarão region, but also the rest of southern Brazil.
\end{abstract}

Keywords: Sociolinguistics; linguistic variation; pronoun me.

\title{
1. Introdução
}

O Jaguarão é uma cidade do extremo sul do Estado do Rio Grande do Sul, Brasil, fundada em 1802 e elevada à categoria de cidade em 1832, e faz fronteira com a cidade de Rio Branco, Cerro Largo, Uruguay. Jaguarão teve grande importância econômica, principalmente no século XIX, com o comércio de escravos. As cidades são separadas pelo rio Jaguarão, sendo que o contato entre elas é feito pela Ponte Internacional Barão de Mauá, inaugurada em 1930. Atualmente ambas vivem em harmonia, mas antigamente essa região foi marcada por constantes batalhas entre os dois países. Duas coisas são fundamentais na hora de caracterizar esses dois povos. A primeira é a cultura, e a segunda é a língua.

A cultura fronteiriça uruguaia é proveniente, em grande maioria, de influências linguísticas ibéricas; no entanto, atualmente, tem grande influência da cultura brasileira, sendo que essa influência apresenta-se com maior porcentagem da cultura Rio Grandense do que do Brasil como um todo. Já a cultura fronteiriça brasileira é originária de uma mescla de outras culturas, como: italiana, alemã, brasileira de um modo geral, entre outras, e também recebeu muita influência da cultura fronteiriça/espanhola.

Segundo o pesquisador Couto (2011, p. 376), nos limites entre o Brasil e o Uruguai, há dois tipos de fronteiras geográficas. Um deles é constituído de cidades interligadas por ruas, em que os limites entre países podem ocorrer em uma ou mais ruas, como é o caso de Santana do Livramento, no Rio Grande do Sul, Brasil, e Rivera, no Uruguai. O outro tipo de fronteira geográfica é denominado pelo autor de Acidente Geográfico, ou seja, um rio, em que se enquadra, como exemplo, a cidade de Jaguarão, no Brasil, e Rio Branco, no Uruguai. Neste contexto de fronteira, segundo Couto (p. 383-388), o contato entre habitantes de ambas as cidades "não é intensa e íntima" como em fronteiras separadas por ruas. Embora este contato 
não seja tão intenso, é possível perceber, neste estudo, que as duas línguas se encontram e se mesclam, possibilitando a ocorrência de fenômenos linguísticos.

A língua marca uma distinção entre as duas cidades, tanto na forma sintática quanto semântica, mas isso não interfere muito no processo de comunicação, pois a comunicação é realizada tanto na mesma língua (uma boa parte dos fronteiriços são bilíngues) quanto cada um em sua língua (uma porcentagem muito significativa não domina o outro idioma, mas o compreende perfeitamente). Sendo assim, ao mesmo tempo em que se distinguem em alguns pontos se unem em outros, pois ambas se entrelaçam, e desse modo, é perceptível a influência que tanto a cultura quanto a língua perpetram indistintamente nas duas sociedades. A partir desse ponto de vista e de acordo com as palavras de Rizzon (2012, p. 123), a fronteira é “[...] entendida por sua referência simbólica e por seu caráter cultural [...]”, sendo assim, ela “[...] transcende ao imaginário, pondo em evidência outras percepções geográficas”.

A partir destas considerações, a língua é o que mais nos interessa, neste estudo, pois buscamos, por meio dela, perceber como tal influência caracteriza a sintaxe do português falado na região jaguarense. A análise permitirá tentar entender como é formada a estrutura sintática falada nessa região, bem como suas influências e estranhamentos dos forasteiros ao terem contato com ela. Vale ressaltar que o português falado no Brasil (chamado português brasileiro), assim como as outras variedades da língua portuguesa, é derivado do Latim, e tem uma forte influência do Grego (e de outras línguas, em menor grau), tendo como línguas irmãs o Italiano, o Francês e o próprio Espanhol. Esta proximidade e o contato direto entre as línguas, propiciado pela interação entre os indivíduos das duas cidades, possibilitam para que haja o aparecimento de fenômenos linguísticos.

Por meio das informações apresentadas acima, busca-se investigar o emprego do clítico de primeira pessoa do singular me, no dialeto jaguarense, na fronteira sul do Rio Grande do Sul. O interesse por estudar a utilização do pronome me surge do estranhamento causado nos discentes da Unipampa, (Universidade Federal do Pampa, Campus Jaguarão), oriundos de outros Estados, assim como deve ocorrer com turistas ou pessoas vindas de outras partes do país, que têm o primeiro contato com a forma sintática desta variedade linguística falada nessa região, tomando como exemplo inicial a frase: hoje me acordei às 07:00 da manhã. O estranhamento ocorre porque ao escutar esta frase muitos indivíduos, que não pertencem a essa cultura, têm a impressão de que uma parte do falante está acordada enquanto a outra dorme, e espera o momento certo para acordá-la, oferecendo, assim, bases e dados de estudos linguísticos. 


\title{
2. Referencial teórico
}

O interessante em relação a esse fenômeno é o fato de se observar, no falar jaguarense, a presença de pronomes átonos (mais especificamente, neste trabalho, a presença do pronome átono me) em estruturas nas quais, em outras regiões do país, já não são mais tão frequentes (DUARTE; RAMOS, 2015) - o que causa estranhamento em falantes brasileiros oriundos de outras regiões do país. Temos aí um caso de variação diatópica, ou seja, variação linguística condicionada por fatores geográficos. Como explicam Coelho et al. (2015, p. 14), a Sociolinguística considera a existência de diferentes tipos de variação linguística, que por sua vez dão origem às diferentes variedades observadas:

\begin{abstract}
Damos o nome de variedade à fala característica de determinado grupo. A partir de critérios geográficos, podemos isolar, por exemplo, a variedade gaúcha, a manauara, e a variedade da Zona Leste de São Paulo; a partir de critérios sociais, podemos pensar, por exemplo, na variedade dos falantes mais escolarizados, na variedade dos falantes mais jovens e na variedade das mulheres; também podemos escolher outros critérios, como a ocupação/profissão (a variedade dos advogados, por exemplo) ou algum hábito que unifique os falantes [...].
\end{abstract}

Ainda segundo os autores, no fenômeno de variação linguística é importante fazer a distinção entre variável e variante, sendo que os sociolinguistas chamam de "[...] variável o lugar na gramática em que se localiza a variação [...]”, e “[...] de variantes as formas individuais que 'disputam' pela expressão da variável [...]" (p. 17). Deste modo, podemos dizer que esse estudo está analisando a variável linguística "expressão do clítico de primeira pessoa do singular me", a partir das variantes "utilização do pronome oblíquo átono me" e a "não utilização do pronome oblíquo átono me", implicando, assim, em duas formas sintáticas distintas.

A segunda variante implica mais de uma forma sintática possível, a depender da função sintática desempenhada pelo pronome átono. Por exemplo, em (1), o me desempenha a função de complemento indireto do verbo emprestar, que na variante "não utilização do pronome átono me" pode ser expressa tanto por um pronome oblíquo tônico (2a) quanto por um complemento foneticamente não realizado (nulo) recuperável no contexto (2b):

(1) Me empresta a caneta?

(2) a. Empresta a caneta pra mim? 
b. $\varnothing^{3}$ empresta a caneta?

De modo geral, no português brasileiro, a forma me é empregada como complemento verbal, podendo alternar com a forma preposicionada mim nos contextos em que a forma para + SN também possa ser empregada (PERINI, 2010, p. 118). Duarte e Ramos (2015) notam que o me é empregado tanto em função acusativa quanto em função dativa e reflexiva. Nas funções acusativa e dativa, embora o clítico me seja apontado como preferencial em relação às demais alternativas (eu, mim e nulo), há presença de outras formas. Quanto à função reflexiva, as autoras apontam variação diatópica; não há dados específicos sobre o Rio Grande do Sul, mas é possível perceber uma tendência geral ao uso de clíticos na região sul.

Os exemplos a seguir ilustram, respectivamente, usos do pronome me como complemento indireto, complemento direto, pronome reflexivo, e ainda como parte da conjugação verbal (os chamados verbos pronominais):
a. Me alcança a caneta?
b. O Pedro me convidou para a festa.
c. Eu me barbeio todos os dias.
d. Eu me queixei com a professora.

Sabe-se que um clítico pode ser apagado caso seu referente esteja saliente no discurso. Também é sabido que há uma tendência ao apagamento dos pronomes reflexivos e de verbos pronominais em algumas variedades do português brasileiro, em especial na variedade mineira (BAGNO, 2011, p. 584). Os exemplos (4) e (5) abaixo ilustram tais possibilidades:

a. Ø alcança a caneta?

b. - O que você vai fazer amanhã?

- O Pedro Ø convidou para a festa.

(5) a. Eu $\emptyset$ barbeei antes de sair.

b. Eu Ø formei em Letras no ano passado.

Paviani (2004), analisando o uso do pronome me na região de Flores da Cunha, na serra gaúcha, conclui que este pronome não é empregado apenas como complemento verbal,

\footnotetext{
${ }^{3} \mathrm{O}$ símbolo "Ø" indica apagamento do pronome.
} 
mas também é muito produtivo como dativo não-argumental "enfático" de posse (6a), de interesse (6b) e ético $(6 c)^{4}$ :
a. Ele sempre me muda as coisas de lugar.
b. Ele me levou embora as pedras com caminhão.
c. Meu filho não me come feijão.

Os dados coletados por Paviani permitem entrever usos do pronome átono me incomuns à fala de outras regiões do país, que a autora atribui à interferência da língua italiana, tendo em vista se tratar de uma região de colonização italiana, cujos habitantes são, em grande medida, bilíngues. Como a variante "utilização do pronome átono me" também tem grande ocorrência na região de Jaguarão, uma questão a ser investigada é a ocorrência do me enfático, semelhante aos achados de Paviani. Essa é uma possibilidade concreta, tendo em vista a localização geográfica de Jaguarão e a influência da língua espanhola.

Quanto à posição dos clíticos, segundo as gramáticas normativas do português, a colocação dos pronomes pode ser enclítica, proclítica ou mesoclítica, a depender do contexto sintático, sendo a ênclise considerada a posição básica (CUNHA; CINTRA, 2013). No entanto, no português brasileiro, nota-se a preferência pela utilização do pronome proclítico ao verbo principal, isto é, antes do verbo principal, seja em início, meio ou final de oração (PERINI, 2010; CASTILHO, 2010), chegando-se a 92\% de próclise em dados do português culto falado (CYRINO; NUNES; PAGOTTO, 2015, p. 61). Já em espanhol, há próclise com verbos únicos, ênclise com infinitivos, gerúndios e imperativos, e tanto a ênclise ao verbo principal quanto a próclise ao auxiliar são possíveis com locuções verbais. Crucialmente, não são possíveis a ênclise ao verbo auxiliar ou a próclise ao verbo principal. Assim, também observaremos a posição do clítico me em relação aos verbos nos dados coletados, de modo a identificar se a tendência de colocação se aproxima à do espanhol.

\section{Metodologia}

O corpus de análise da pesquisa proposta por este trabalho foi coletado por meio de observações em conversas informais, tanto na Unipampa-Jaguarão quanto no cotidiano da cidade, em um período inferior a dois meses e sem a intervenção de questionários préesquematizados. Foram coletadas 39 frases, sem levar em considerações variáveis

\footnotetext{
${ }^{4}$ Exemplos retirados de Paviani (2004).
} 
extralinguísticas como gênero, idade ou grau de escolaridade dos falantes, ou seja, não houve distinção entre as partes analisadas, pois, por meio das observações empíricas, pode-se perceber que essas variáveis não influenciam no uso dos pronomes.

\section{Análise de dados}

Os dados coletados foram agrupados conforme a função do pronome me: complemento direto, complemento indireto, pronome reflexivo, verbo pronominal ou dativo não-argumental ("enfático"). Optou-se pela não subdivisão dos dativos não-argumentais em éticos, de posse ou de interesse, pois tal distinção não se mostrou relevante.

Os quadros a seguir ilustram cada função do pronome me. A coluna da esquerda traz os dados coletados, e a coluna da direita apresenta possíveis formas da variante sem o uso do pronome.

Quadro 1 - me complemento direto

\begin{tabular}{|l|l|}
\hline Ele te conhece? Sim, ele me conhece. & Ele te conhece? Sim, $\varnothing$ conhece. \\
\hline Me deixou perdido. & Deixou eu perdido. \\
\hline Me chamaram de louca & Chamaram eu de louca. \\
\hline
\end{tabular}

O Quadro 1 sintetiza os casos de me como complemento direto encontrados nos dados (cabe ressaltar que foram apenas 5 os casos de me acusativo). Enquanto o primeiro dado permite o simples apagamento do pronome, devido ao contexto anterior, nos dois últimos isso não é possível. É preciso substituir o pronome átono pelo pronome reto eu, ou então faz-se necessária uma paráfrase como estratégia de "esquiva" ("fiquei perdido", "disseram que eu sou louca"). Nesses casos, temos construções de predicativo do objeto, em que o complemento verbal vem acompanhado de uma expressão predicativa ("perdido" e "de louca", respectivamente) que precisa se aplicar a um referente. Isso talvez explique as diferentes possibilidades de (não) apagamento do pronome.

Quadro 2 - me complemento indireto

\begin{tabular}{|l|l|}
\hline Ele me trouxe o livro hoje à tarde. & Ele trouxe o livro pra mim hoje à tarde. \\
\hline Me empresta cinco pila? & $\begin{array}{l}\text { Empresta cinco pila pra mim? } \\
\varnothing \text { empresta cinco pila? }\end{array}$ \\
\hline Me consegue o celular da Ana? & $\begin{array}{l}\text { Consegue o celular da Ana pra mim? } \\
\varnothing \text { consegue o celular da Ana? }\end{array}$ \\
\hline Me dá um mate. & $\begin{array}{l}\text { Dá um mate pra mim. } \\
\varnothing \text { dá um mate. }\end{array}$ \\
\hline
\end{tabular}


O Quadro 2 ilustra usos do pronome me como complemento indireto, a que correspondeu a maior fatia dos dados coletados (18 de 39), embora haja verbos repetidos. Nestes casos, é categoricamente possível a substituição do pronome átono me pelo pronome tônico mim. Chama a atenção o fato de o pronome átono ser tão frequentemente empregado, mesmo em ocorrências nas quais fica evidente pelo contexto a referência do beneficiário da ação verbal. É o caso dos três últimos exemplos, em que temos pedidos/interpelações; neles, seria perfeitamente possível o apagamento do pronome.

Quadro 3 - me reflexivo/verbo pronominal

\begin{tabular}{|l|l|}
\hline Guris, vou me atrasar um pouco. & Guris, vou Ø atrasar um pouco. \\
\hline Meu Deus, me esqueci o capacete! & Meu Deus, Ø esqueci o capacete! \\
\hline Monto na moto e me vou embora. & Monto na moto e Ø vou embora. \\
\hline Hoje me acordei às sete da manhã. & Hoje Ø acordei às sete da manhã. \\
\hline Eu vi que tava errado e me corrigi. & Eu vi que tava errado e Ø corrigi. \\
\hline Eu já me livrei da apresentação. & $\begin{array}{l}\text { ??Eu já Ø livrei da apresentação. } \\
\text { Eu já estou livre da apresentação. }\end{array}$ \\
\hline Nas férias eu vou me tratar. & $\begin{array}{l}\text { ??Nas férias eu vou Ø tratar. } \\
\text { Nas férias eu vou ao médico. }\end{array}$ \\
\hline
\end{tabular}

Já no Quadro 3 temos exemplificados casos do me como pronome reflexivo e em verbos pronominais, também razoavelmente frequentes nos dados, ainda que não tão produtivos quanto os complementos indiretos. Neles, observa-se que ora é possível simplesmente apagar o pronome, ora não. Particularmente, os dois últimos dados parecem forçar paráfrases, novamente numa estratégia de "esquiva" do uso do pronome, como havia acontecido também com o me complemento direto. Uma possível explicação para a impossibilidade de apagamento do pronome nesses casos é o fato de os verbos "livrar" e "tratar" necessitarem de um complemento; a ausência do pronome faz com que os enunciados fiquem "sem sentido", uma vez que não é possível saber quem ou o que foi livrado ou o que será tratado.

Quadro 4 - me dativo não-argumental

\begin{tabular}{|l|l|}
\hline Eu via ela andando na barca e me afrouxava as perna. & $\begin{array}{l}\text { Eu via ela andando na barca e afrouxava as minhas } \\
\text { pernas. }\end{array}$ \\
\hline Me caiu os butiá do bolso. & Caiu os butiá do meu bolso. \\
\hline Estava cozinhando e me cortei a mão com a faca. & $\begin{array}{l}\text { Estava cozinhando e } \emptyset \text { cortei a mão com a faca. } \\
\text { Estava cozinhando e cortei a minha mão com a faca. }\end{array}$ \\
\hline
\end{tabular}


RELACult - Revista Latino-Americana de Estudos em Cultura e Sociedade

Revista Latinoamericana de Estudios en Cultura y Sociedad | Latin American Journal of Studies in Culture and Society V. 02, Ed. Especial, dezembro, 2016, p. 654-664| periodicos.claec.org e-ISSN 2016/Atual: 2525-7870 | e-ISSN 2015/2016: 2447-018X

\begin{tabular}{|l|l|}
\hline $\begin{array}{l}\text { Meu cachorro é louco, ele entra correndo na sala e me } \\
\text { derruba o mate. }\end{array}$ & $\begin{array}{l}\text { Meu cachorro é louco, ele entra correndo na sala e } \varnothing \\
\text { derruba o mate. }\end{array}$ \\
\hline Não vai me comer bergamota aqui dentro do ônibus. & Não vai $\varnothing$ comer bergamota aqui dentro do ônibus. \\
\hline Podes me trazer ele agora? É que me acabou o gás. & Podes me trazer ele agora? É que $\varnothing$ acabou o gás. \\
\hline
\end{tabular}

Por sua vez, o Quadro 4 mostra que foram encontrados, nos dados analisados, casos semelhantes aos discutidos por Paviani (2004). Vemos que, em sua maioria, os pronomes podem ser apagados sem maior prejuízo da estrutura mesmo quando não há um referente saliente, o que é esperado, visto que se trata de pronomes não-argumentais, ou seja, pronomes que não são exigidos pelo verbo. O fato de que, por vezes, é possível substituir o pronome átono por um pronome possessivo é esperado, pois um dos dativos enfáticos é justamente o dativo de posse.

Interessante observar também o fato de que são atestadas ocorrências dos pronomes retos de terceira pessoa ele/ela em posição de complemento verbal, algo condenado pela gramática tradicional, mas absolutamente corriqueiro no português brasileiro falado:
a. Eu via ela andando na barca $[\ldots]$.
b. Podes me trazer ele agora?

Essas estruturas passam a ser possíveis no português brasileiro a partir do momento em que os pronomes átonos de terceira pessoa do singular o/a/os/as caem em desuso, o que, por sua vez, se dá devido às mudanças na colocação pronominal - passagem de um sistema enclítico para um sistema proclítico (CASTILHO, 2010, p. 480). O fato de encontrarmos essas estruturas no português falado em Jaguarão indica que, embora a produtividade do pronome átono me possa ser explicada pelo contato linguístico com o espanhol, predomina nessa variedade a sintaxe do português brasileiro.

Evidência adicional disso é a posição do pronome me: percebe-se que em 100\% dos casos o pronome aparece proclítico ao verbo principal, como no português brasileiro. Em especial, os exemplos em (8) apresentam uma colocação impossível em espanhol: próclise ao verbo principal em locuções verbais:

(8) a. Guris, vou me atrasar um pouco.

b. Nas férias eu vou me tratar.

c. Não vai me comer bergamota aqui dentro do ônibus.

d. Podes me trazer ele agora? 


\section{Considerações finais}

A partir dos dados levantados acima, pôde-se perceber que o pronome oblíquo átono me é usado produtivamente na região fronteiriça da cidade de Jaguarão-RS, e que o estranhamento causado nos forasteiros, ao chegarem nessa região, está ligado à não utilização do pronome oblíquo em suas falas, formando o apagamento do pronome em si. Em particular, chama a atenção o fato de o pronome me ser bastante usado em construções reflexivas/verbos pronominais e como dativo não-argumental, algo não tão comum em outras regiões do Brasil. Também, mesmo nos casos em que tal pronome é empregado produtivamente no restante do país, os dados analisados levam à conclusão de que a frequência de uso do me no contexto analisado é maior - caso dos complementos indiretos com saliência contextual do beneficiário, em que a presença do pronome não é necessária para a interpretação do enunciado.

Ainda que não se tenham utilizado dados de outros pontos do estado, pode-se inferir, por meio de dados presentes em outras obras (p. ex., Paviani, 2004), que o uso do me está presente não somente na região analisada, mas também em outras partes do Estado. Assim como Paviani credita a presença do dativo me na região de imigração italiana à interferência do italiano, acreditamos que a produtividade de me observada na fala jaguarense seja por influência, ainda que não absoluta, do contato com o espanhol. Destaca-se, nesse sentido, a existência de expressões como "me dormi" e "não me fica mais" ("não tem mais", referindose, por exemplo, a uma mercadoria em uma loja), importadas diretamente do espanhol uruguaio e muito recorrentes na fala jaguarense.

Conclui-se, então, que o emprego do pronome átono me é uma característica da região sul do Brasil e tem uma grande ocorrência na sintaxe usada em Jaguarão, visto que os dados analisados foram coletados em um curto espaço de tempo e não houve dificuldades em recolhê-los.

\section{Referências}

BAGNO, Marcos. Gramática pedagógica do português brasileiro. São Paulo: Parábola, 2011.

CASTILHO, Ataliba T. de. Nova gramática do português brasileiro. São Paulo: Contexto, 2010.

COELHO, Izete; GÖRSKI, Edair; SOUZA, Christiane; MAY, Guilherme. Sociolinguística. São Paulo: Contexto, 2015. 

e-ISSN 2016/Atual: 2525-7870 | e-ISSN 2015/2016: 2447-018X

COUTO, H. H. Contato entre português e espanhol na fronteira Brasil-Uruguai. In: Mello, H.; Altenhofen, C. V.; Raso, T. (Orgs.). Contatos linguísticos no Brasil. Belo Horizonte: Editora da UFMG, 2011. p. 369-395.

CUNHA, Celso; CINTRA, Lindley. Nova gramática do português contemporâneo. 6. ed. Rio de Janeiro: Lexicon, 2013.

CYRINO, Sonia; NUNES, Jairo; PAGOTTO, Emilio. Complementação. In: KATO, Mary A.; NASCIMENTO, Milton do (Orgs.). A construção da sentença. São Paulo: Contexto, 2015. p. 37-80. (Gramática do português culto falado no Brasil, v. 2).

DUARTE, Maria Eugênia; RAMOS, Jânia. Variação nas funções acusativa, dativa e reflexiva. In: MARTINS, Marco Antonio; ABRAÇADO, Jussara (Orgs.). Mapeamento sociolinguístico do português brasileiro. São Paulo: Contexto, 2015. p. 173-195.

PAVIANI, Neires Maria Soldatelli. O pronome ético: uma característica dialetal. Caxias do Sul: EDUCS, 2004.

PERINI, Mário A. Gramática do português brasileiro. São Paulo: Parábola, 2010.

RIZZON, C. G. Outras geografias em literaturas de fronteira. Para Onde!?, Porto Alegre, v. 6, p. 114-124, 2012. Disponível em:

<http://seer.ufrgs.br/paraonde/article/viewFile/36488/23902>. Acesso em: 10 jul. 2015. 